\title{
Effects of PLD deposited ZnO seed layer on the structure and morphology of ZnO nanowires prepared by CBD method
}

\author{
Shan-shan Lu", a, Ying Huang, b, Jia-yuan Qin ${ }^{1}$, Zu-kang Mo' ${ }^{1}$, Wu-lin Xie', \\ Yue-chun $\mathrm{Fu}^{1}$, Huan $\mathrm{He}^{1}$, Li-feng Bian², Shu-long Lu², Xiao-ming Shen ${ }^{1, \mathrm{c}}$ \\ ${ }^{1}$ Guangxi Key Laboratory of Processing for Nonferrous Metal and Featured Materials, College of \\ Materials Science and Engineering, Guangxi University, Nanning, 530004, China \\ ${ }^{2}$ Key Laboratory of Nanodevices and Applications, Suzhou Institute of Nano-Tech and Nano-Bionics, \\ Chinese Academy of Sciences, Suzhou, 215123, China \\ a1393901254@qq.com, bhyamps@163.com, docsjh@gxu.edu.cn
}

Keywords: $\mathrm{ZnO}$ seed layers, crystallinity, pulsed laser deposition, chemical bath deposition.

Abstract. ZnO seed layers have been deposited on ITO substrates by pulsed laser deposition (PLD) at different substrate temperatures. The crystalline structure, morphology of $\mathrm{ZnO}$ nanowires were characterized by X-ray diffraction (XRD), atomic force microscopy (AFM) and scanning electron microscopy (SEM). The effects of different seed layers on the crystalline structure and morphology of $\mathrm{ZnO}$ nanowires were investigated. The results show that the hexagonal wurtzite structure of $\mathrm{ZnO}$ seed layers are obtained when the substrate temperature is $200^{\circ} \mathrm{C}$. However, the $\mathrm{ZnO}$ seed layers are amorphous films at $150^{\circ} \mathrm{C}$. Vertically aligned $\mathrm{ZnO}$ nanowires are obtained by suitable CBD method on the $\mathrm{ZnO}$ seed layers with good crystallinity.

\section{Introduction}

In recent years, dye sensitized solar cells (DSSCs) have received great attention as one of the third generation solar cells, because of their cheap raw materials, simple production process, high photoelectric conversion efficiency and environmental friendliness [1]. As a wide band gap semiconductor, $\mathrm{TiO}_{2}$ has played a significant role in the dye sensitized solar cells [2]. However, with the rapid development of DSSCs, researchers are now looking for other semiconductor materials which can replace $\mathrm{TiO}_{2}$, such as $\mathrm{CdSe}, \mathrm{CdS}$ and $\mathrm{ZnO}$ [3]. Among these candidates, $\mathrm{ZnO}$ is the most potential light absorbing material, due to its wide band gap $(\sim 3.37 \mathrm{eV})$, high electron mobility, and its good optical, electrical, magnetic and piezoelectric properties. Therefore, it can be used to make light emitting diodes, thermoelectric devices and gas sensors, and so on [4]. Besides, as an electrode material, $\mathrm{ZnO}$ can improve the absorption of sensitization agent, electron transport rate and light absorption by light trapping effect [5]. At present, there are many different methods to prepare $\mathrm{ZnO}$, for instance, chemical vapor deposition (CVD) and spray pyrolysis, etc. But they are expensive and complex which are not suitable for industrial production [6]. On the other hand, chemical bath deposition (CBD) is a better choice due to its lower cost and simpler requirement for equipment.

In this paper, $\mathrm{ZnO}$ seed layers were prepared on ITO substrates by pulsed laser deposition (PLD). Then $\mathrm{ZnO}$ nanowires were grown on $\mathrm{ZnO}$ seed layers by chemical bath deposition (CBD) method. The effects of different $\mathrm{ZnO}$ seed layers and processing parameters on the morphologies of $\mathrm{ZnO}$ nanowires have been investigated in detail, which help us obtain optimal conditions for preparing high length-diameter ratio $\mathrm{ZnO}$ nanowires for their applications in dye sensitized solar cells.

\section{Experimental}

$\mathrm{ZnO}$ seed layers were prepared by LMBE-450 pulsed laser deposition system. First, the ITO substrates were cleaned by ultrasonic cleaner in acetone, ethyl alcohol and de-ionized water for 10 min, respectively. Second, $\mathrm{ZnO}$ seed layers were deposited on ITO substrates for 1 hour by ablating 
the $\mathrm{ZnO}$ ceramic target $(99.99 \%)$ using $\mathrm{KrF}$ pulsed laser $(248 \mathrm{~nm})$. The substrate temperature was varied from $150^{\circ} \mathrm{C}$ to $200^{\circ} \mathrm{C}$. Finally, the seed layer was annealed under vacuum condition at $200^{\circ} \mathrm{C}$ for $1 \mathrm{~h}$ after deposition.

The $\mathrm{ZnO}$ seed layered ITO substrates were immersed in the aqueous solutions consisting of $50 \mathrm{mM}$ of hexamethylenetetramine, $50 \mathrm{mM}$ of zinc nitrate hexahydrate, $4.5 \mathrm{M}$ of polyethyleneimine (PEI). Hydrothermal syntheses were carried out at $95^{\circ} \mathrm{C}$ for $9 \mathrm{~h}$ in the water bath. After the hydrothermal reaction, the $\mathrm{ZnO}$ nanowires grown on ITO substrates were rinsed with de-ionized water and then air dried. In the end, the $\mathrm{ZnO}$ nanowires were annealed in air at $400^{\circ} \mathrm{C}$ for $30 \mathrm{~min}$.

The crystalline structure of $\mathrm{ZnO}$ nanowire was characterized by X-ray diffraction (Rigaku DIMAX 2500). For the morphology evolution of the $\mathrm{ZnO}$ nanowires, atomic force microscope (Agilent 5500 AFM) and scanning microscope (Hitachi SU8020 FE-SEM) were used.

\section{Results and discussions}

The $\mathrm{ZnO}$ seed layers were grown on ITO substrate while the substrate temperature was set at $150^{\circ} \mathrm{C}$ and $200^{\circ} \mathrm{C}$. Fig. 1 shows XRD patterns of $\mathrm{ZnO}$ seed layers deposited at various substrate temperatures. When the substrate temperature is $150^{\circ} \mathrm{C}$, the diffraction peaks in the XRD patterns correspond to the ITO substrate with no peaks from $\mathrm{ZnO}$ seed layer. It can be seen that the $\mathrm{ZnO}$ seed layers form amorphous films which have not crystal orientation. When the substrate temperature rises up to $200^{\circ} \mathrm{C}$, two diffraction peaks appear at $34.6^{\circ}$ and $63.1^{\circ}$, corresponding to the (002) and (103) surfaces of hexagonal wurtzite structure $\mathrm{ZnO}$. Obviously, the (002) peak is stronger than (103) peak, indicating that the $\mathrm{ZnO}$ seed layers are oriented along the c-axis direction.

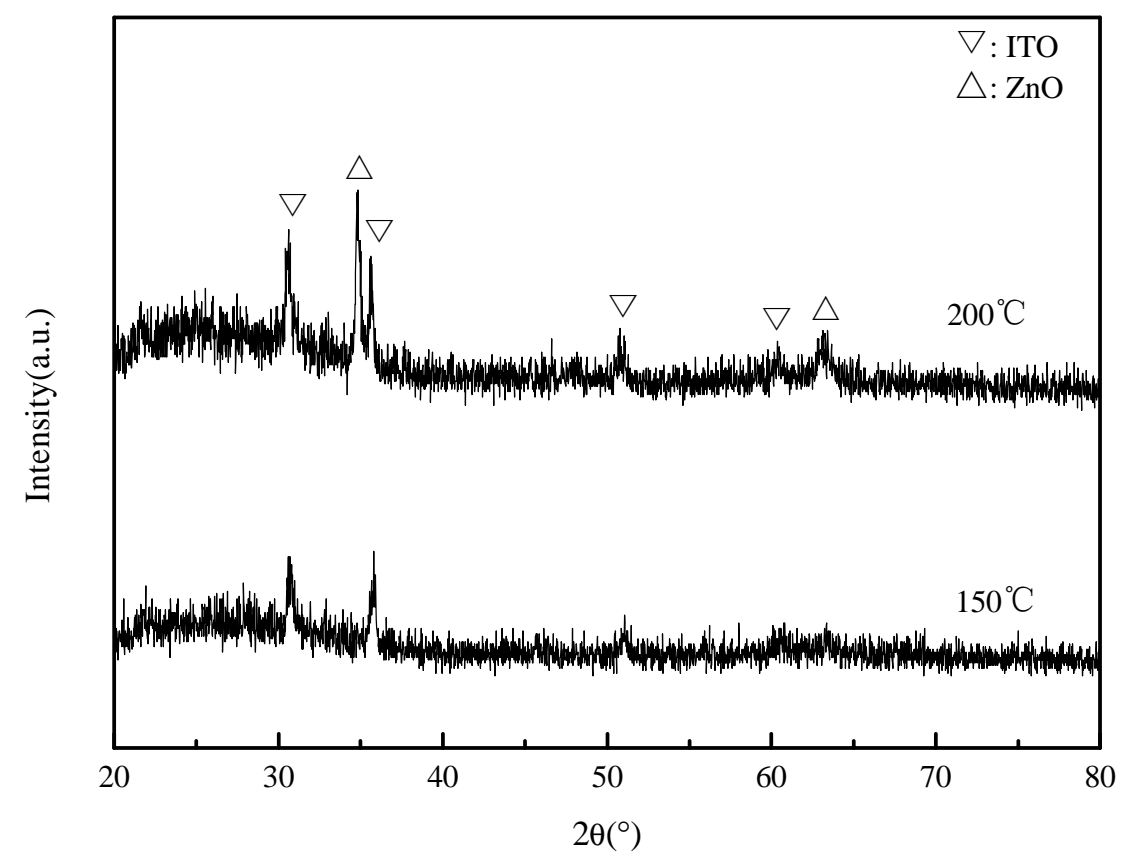

Fig.1 XRD patterns of $\mathrm{ZnO}$ seed layers deposited at different substrate temperatures

From the AFM images (as shown in Fig. 2), the ZnO seed layers are grown on the ITO substrate at different temperatures. For the effects of surface roughness of $\mathrm{ZnO}$ seed layers, Fig.2(a) shows that the surface of seed layer is relatively flat when the substrate temperature is $150^{\circ} \mathrm{C}$, but the crystallites with non-uniform size distribute randomly between the relatively flat areas. However, well-crystallized $\mathrm{ZnO}$ seed layers with uniform grain size are obtained when the substrate temperature set at $200^{\circ} \mathrm{C}$. All of the orientations of the grains are significantly perpendicular to the surface of the 
substrate, and have highly c-axis preferred orientation. When the substrate temperature is low, the slower migration of arriving adatoms on the substrate is not good for the growth of $\mathrm{ZnO}$ nucleation and helps the formation of amorphous structure. With the increase of the substrate temperature, the migration ability of deposited particles is so strong that grains have enough energy to move to the proper positions. Therefore, the crystal quality of $\mathrm{ZnO}$ seed layers is improved at relatively high temperature.
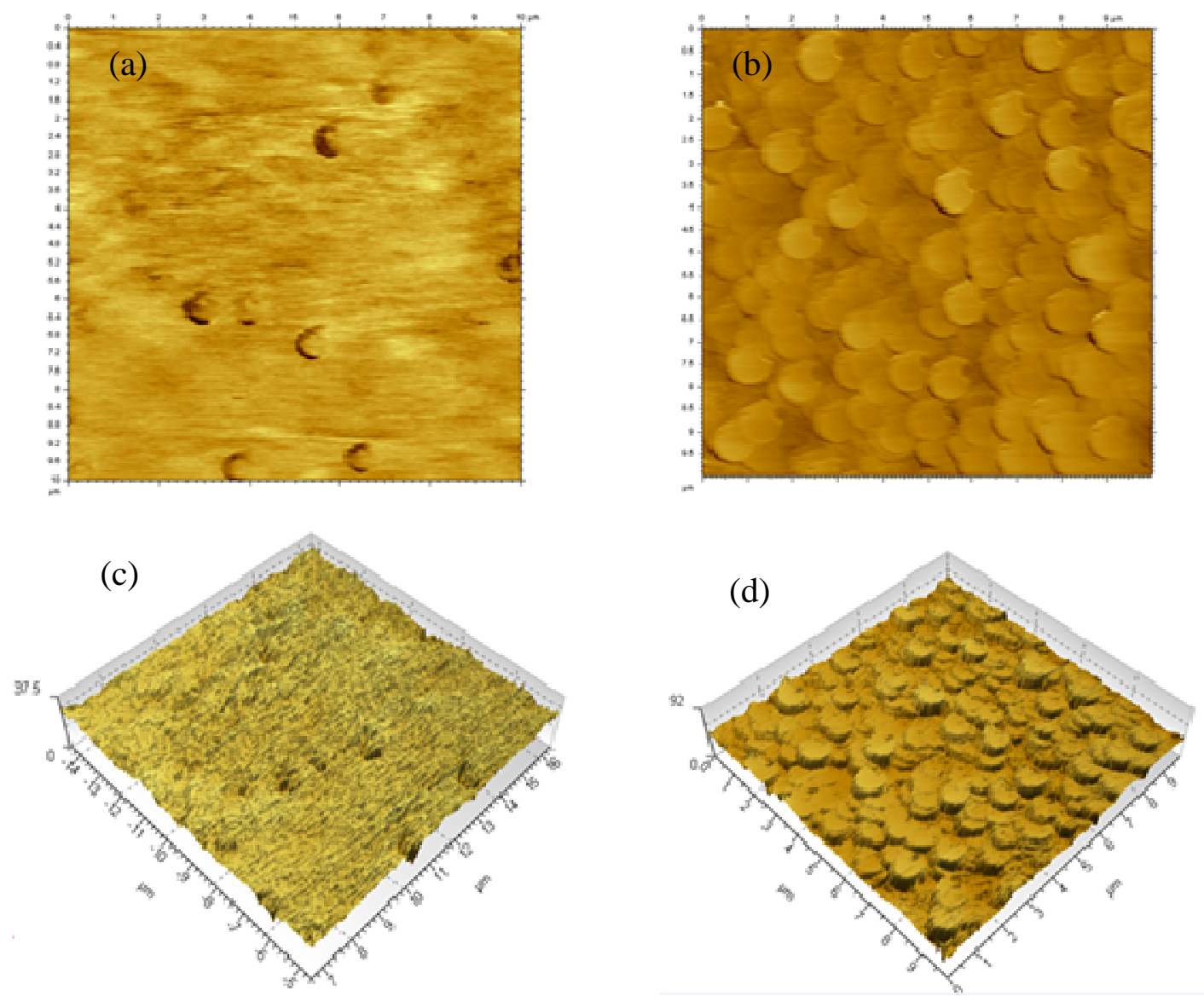

Fig. 2 AFM patterns of $\mathrm{ZnO}$ seed layers evolve with substrate temperature $(10 \mu \mathrm{m} \times 10 \mu \mathrm{m})$ (a) and (c): $150^{\circ} \mathrm{C},(\mathrm{b})$ and (d): $200^{\circ} \mathrm{C}$

Fig.3 shows the SEM images of $\mathrm{ZnO}$ nanowires grown on different $\mathrm{ZnO}$ seed layers. It can be seen that the morphology of $\mathrm{ZnO}$ nanowires is obviously different, due to the various crystallinity and morphology of $\mathrm{ZnO}$ seed layers. In Fig.3(a) and (b), a substrate temperature of $150^{\circ} \mathrm{C}$ results the shape of the cauliflower of $\mathrm{ZnO}$ nanowires with no definite orientation. The reason for this is that $\mathrm{ZnO}$ nanowires grow along the different directions of the seed layer grains, which are amorphous films with unordered arrangement. While the substrate temperature was raised up to $200^{\circ} \mathrm{C}$, not only the $\mathrm{ZnO}$ seed layers have good crystallinity but the $\mathrm{ZnO}$ nanowires almost arranged vertically at the substrate, as shown in Fig.3(c) and (d). In addition, the $\mathrm{ZnO}$ nanowires grow along the [0001] crystal direction of the seed layers, which are confirmed by the results of XRD measurement.

The $\mathrm{ZnO}$ is a typical polar crystal, because $\mathrm{Zn}$ atoms in the c-axis are asymmetrically distributed and in favor of the c-axis. Besides, in the c-axis direction, the crystallographic orientation of the $[\mathrm{ZnO} 4]^{4-}$ coordination tetrahedron is different, and its deviation is $60^{\circ}$ between upper and lower layers. Therefore, the (0001) plane of $\mathrm{Zn}$ atoms are positive surface while the (000-1) plane of Oxygen atoms are negative surface [7]. The positive surface is covered by positive charges that (0001) surface 
attracts negative charges, such as $\mathrm{OH}^{-}$, and then alternately attract $\mathrm{ZnO}^{2+}$ and $\mathrm{OH}^{-}$. Therefore, nucleation and growth of the $\mathrm{ZnO}$ occur on the (0001) surface. The growth rate of $\mathrm{ZnO}$ on (0001) surface is faster than that on the lateral surface, resulting in the $\mathrm{ZnO}$ nanowires grown along c-axis.
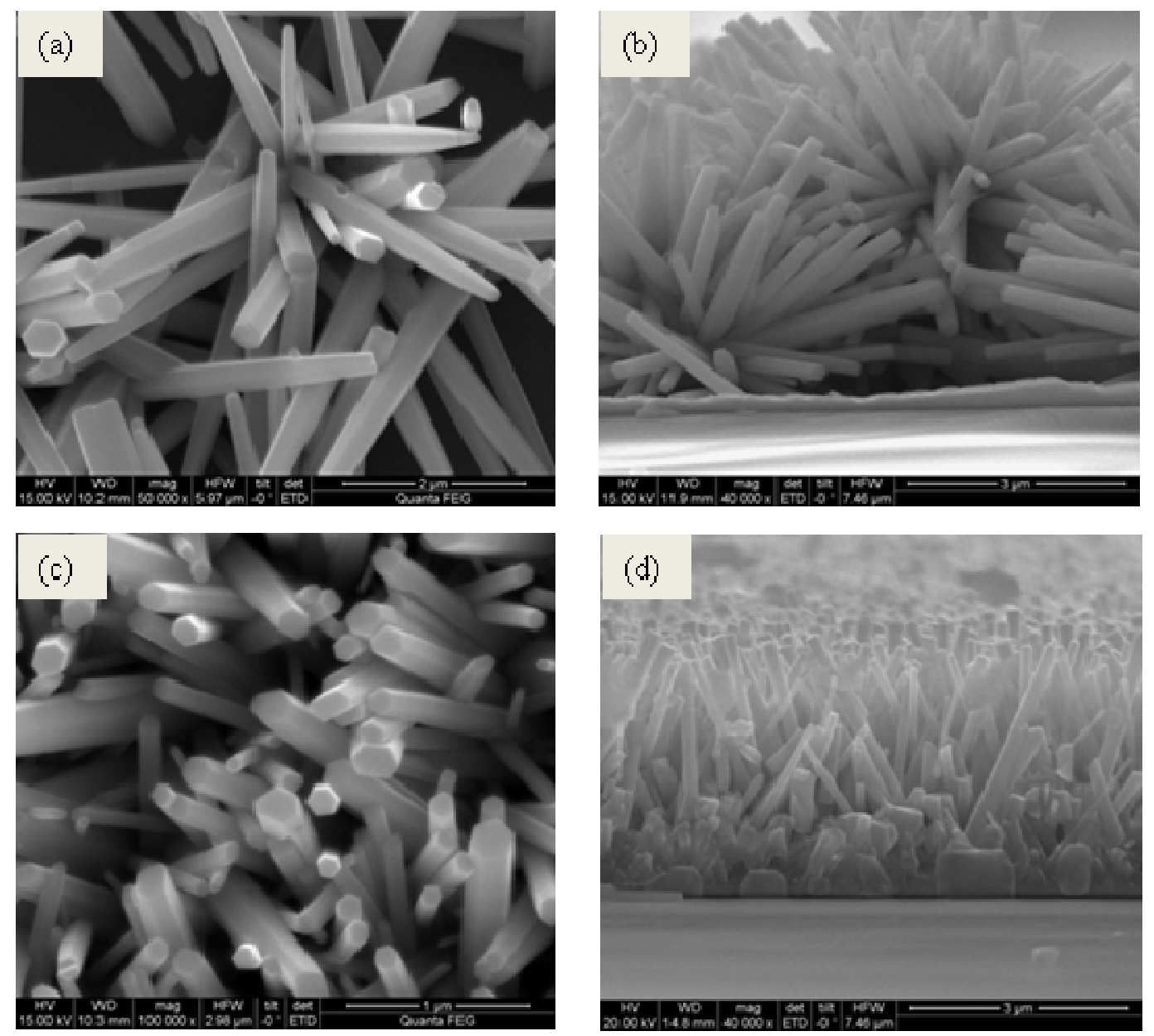

Fig.3 SEM images of the $\mathrm{ZnO}$ nanowires grown on different $\mathrm{ZnO}$ seed layers (a) and (b) $150^{\circ} \mathrm{C}$, (c) and (d) $200^{\circ} \mathrm{C}$

In a word, with the preferential growth along the (0001) surface, $\mathrm{ZnO}$ seed layers can vertically aligne on the ITO substrate when the substrate temperature was $200^{\circ} \mathrm{C}$. However, when the substrate temperature was $150^{\circ} \mathrm{C}$, the $\mathrm{ZnO}$ seed layers formed amorphous films, and the $\mathrm{ZnO}$ nanowires grow along various directions from the disordered crystallites. Gradually, the $\mathrm{ZnO}$ nanowires formed the shape of the cauliflowers. Fig 4 shows the schematic diagram of $\mathrm{ZnO}$ nanowires grown on different $\mathrm{ZnO}$ seed layers deposited at different substrate temperatures. 
(a)

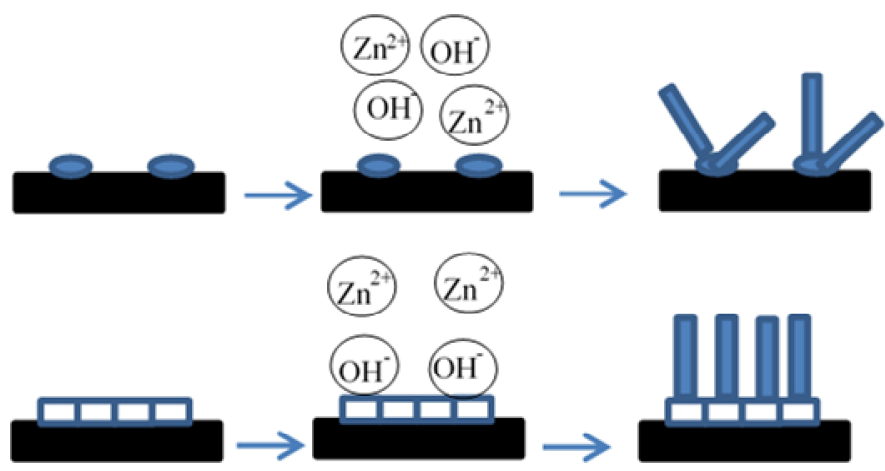

Fig.4 Schematic diagram of $\mathrm{ZnO}$ nanowires grown on different $\mathrm{ZnO}$ seed layers deposited at different substrate temperatures of (a) $150^{\circ} \mathrm{C}$ and (b) $200^{\circ} \mathrm{C}$

\section{Conclusions}

In this study, the $\mathrm{ZnO}$ seed layers have been successfully prepared by the pulsed laser deposition system. When the $\mathrm{ZnO}$ seed layers were deposited on ITO substrate at $200^{\circ} \mathrm{C}$, the ordered arrangement with hexagonal wurtzite structure was obtained, and the disordered amorphous $\mathrm{ZnO}$ seed layers were prepared at $150^{\circ} \mathrm{C}$. Vertically aligned $\mathrm{ZnO}$ nanowires are obtained based on the good crystallinity of $\mathrm{ZnO}$ seed layers, indicating the effects of different seed layers on the crystalline structure and the morphology of $\mathrm{ZnO}$ nanowires.

\section{Acknowledgements}

This work was financially supported by the National Natural Science Foundation (61474030), the Guangxi Natural Science Foundation (2015GXNSFAA139265), the Open Foundation of Key Laboratory of Nanodevices and Applications, Chinese Academy of Sciences (15ZS06), the Foundation of Guangxi Science \& Technology Development Project (1598008-15) and the Foundation of Nanning Municipal Science \& Technology Development Project (20151268).

\section{References}

[1] M. Law, L. Greene, J.C. Johnson, R. Saykally, P.D. Yang: Nature materials Vol. 4 (2005), p. 455

[2] J.F Lei, S.L. Liu, K. Du, S.J. Lv, C.J. Liu, L.Z. Zhao: Electrochimical Acta Vol. 171 (2015), p. 66

[3] Y.M. Meng, Y. Lin, J.Y. Yang: Journal of solid state chemistry, Vol. 210 (2014), p. 160

[4] J. Zhang, X. Li, W. Guo, et al.: Electrochimica Acta Vol. 56(9) (2011), p. 3147

[5] Q.W. Jiang, G.R. Li, S. Liu, et al.: Journal of Physical Chemistry C Vol. 114(31) (2010), p. 13397

[6] V. Bhavanasi, C.B. Singh, D. Datta, V. Singh, et al.: Optical Materials Vol. 35 (2013), p. 1352

[7] Z.X. Ma, Y.Z. Jiang, et al.: Principle and technology of nanometer ZnO (Light Industry Press, Beijing: China 2007). 